\title{
Erratum to: A resting state functional magnetic resonance imaging study of concussion in collegiate athletes
}

\author{
Suzanne M. Czerniak • Elif M. Sikoglu • Ana A. Liso Navarro • \\ Joseph McCafferty • Jordan Eisenstock • J. Herbert Stevenson • \\ Jean A. King • Constance M. Moore
}

Published online: 18 October 2014

(C) Springer Science+Business Media New York 2014

\section{Erratum to: Brain Imaging and Behavior (2014)}

DOI 10.1007/s11682-014-9312-1

The original version of this article unfortunately contained a mistake specifically in the HTML version. Ana A. Liso Navarro's given name and family name were incorrectly assigned. The correct given name should be "Ana A." and her family name "Liso Navarro". The update is also given here.

The online version of the original article can be found at http://dx.doi.org/ 10.1007/s11682-014-9312-1.

S. M. Czerniak · E. M. Sikoglu · A. A. Liso Navarro •

J. Eisenstock

J. McCafferty $\cdot$ J. A. King $\cdot$ C. M. Moore $(\triangle)$

Department of Psychiatry, Center for Comparative Neurolmaging,

University of Massachusetts Medical School, 303 Belmont Street,

Worcester, MA 01604, USA

e-mail: Constance.Moore@umassmed.edu

S. M. Czerniak

e-mail: suzanne.czerniak@umassmed.edu

E. M. Sikoglu

e-mail: muazzez.sikoglu@umassmed.edu

A. A. Liso Navarro

e-mail: aliso@bluewin.ch

J. McCafferty

e-mail: jpm059@bucknell.edu

J. A. King

e-mail: jean.king@umassmed.edu

E. M. Sikoglu • A. A. Liso Navarro $\cdot$ J. Eisenstock $\cdot$ J. A. King $\cdot$

C. M. Moore

Department of Psychiatry, University of Massachusetts Memorial

Medical School, Memorial Campus 119 Belmont Street, Worcester,

MA 01605, USA

e-mail: jordan.eisenstock@umassmemorial.org

A. A. Liso Navarro

Office Médico-Pédagogique, Department of Psychiatry, University of Geneva School of Medicine, Rue David Dufour 1, Case postale 50, 1211 Geneva 8, Switzerland

J. Eisenstock

Department of Neurology, University of Massachusetts Medical School, Worcester, MA, USA

\section{J. H. Stevenson}

Department of Sports Medicine, University of Massachusetts Memorial Medical School, Hahnemann Campus 281 Lincoln Street, Worcester, MA 01605, USA

e-mail: john.stevenson@umassmemorial.org

\section{J. A. King $\cdot$ C. M. Moore}

Department of Radiology, University of Massachusetts Medical

School, Worcester, MA, USA 